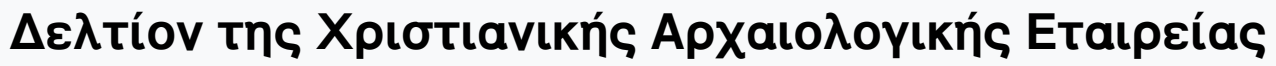

Tóp. 4 (1966)

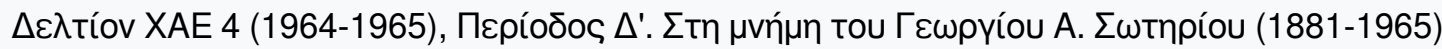

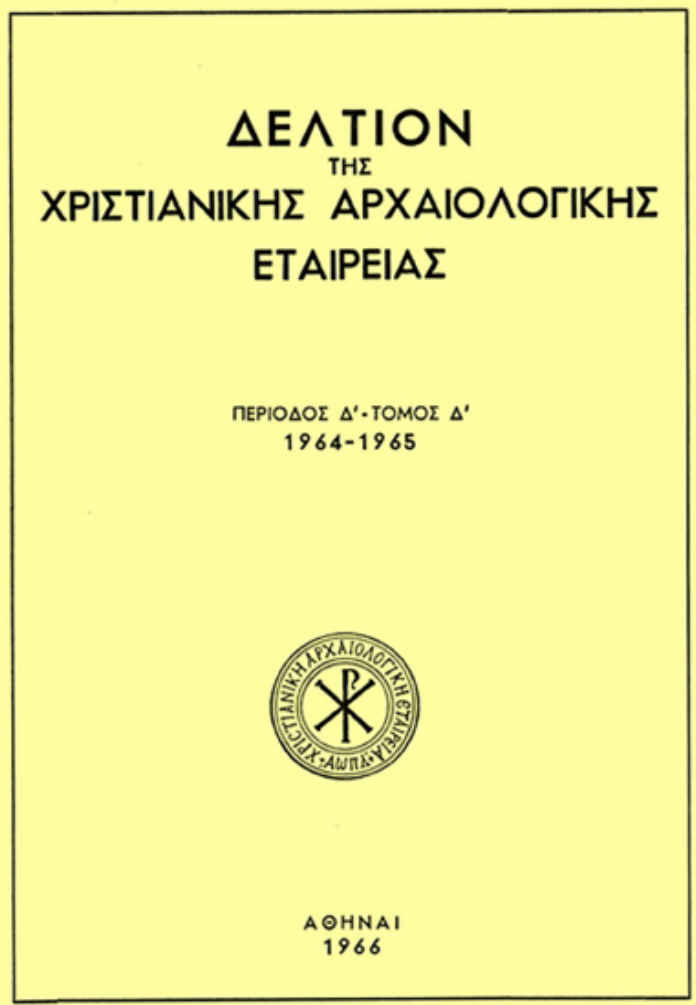

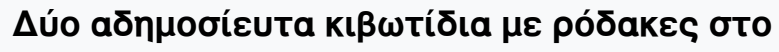

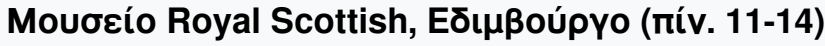

David TALBOT-RICE

doi: $10.12681 /$ dchae.752 


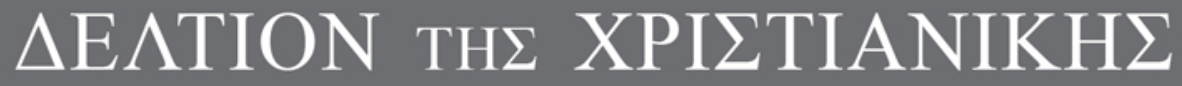 APXAIO $\Lambda$ OГIKH $\Sigma$ ETAIPEIA $\Sigma$}

Two unpublished Rosette Caskets in the Royal Scottish Museum, Edinburgh (pl. 11-14)

David TALBOT-RICE

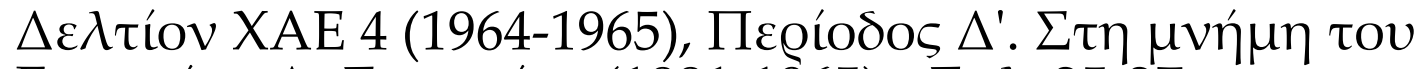

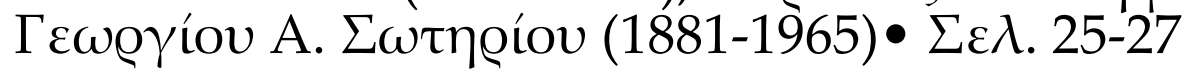

A@HNA 1966 


\section{TWO UNPUBLISHED ROSETTE CASKETS IN THE ROYAL SCOTTISH MUSEUM, EDINBURGH}

(Pl. 11 - 14)

There are in the Royal Scottish Museum at Edinburgh two Rosette Caskets of the usual rectangular form, with sliding top. Though neither of them is to be compared with such a work as the Veroli casket from the artistic point of view, they are both interesting and deserve to be better known, for they were not included by Goldschmidt and Weitzmann in their great corpus ${ }^{1}$, and, apart from a brief mention in the catalogue of the Byzantine Exhibition held ad Edinburgh and London in 1958 \&, they have never been published.

The first of the two (No. 1884; 44;11) is $43 \mathrm{~cm}$. long, $17.4 \mathrm{~cm}$. wide and $11.3 \mathrm{~cm}$. in height. There are four rectangular plaques on the top (Fig. A, Pl. 11), set in a narrow border of ivory bearing an egg and dart pattern and a wider one of the usual rosettes, and the plaques are separated one from another by rosettes. The outer border, below which the lid slides, is adorned with small rosettes and dotted squares, lightly carved, and alternating at wide intervals. The bands of rosettes must have been cut from strips already carved, for little attention has been paid to the position of the actual rosettes.

The front (Fig. B, Pl. 11) and the back (Fig. C, Pl. 11) are each made up of five similar plaques, bordered by rosettes, but the narrow strips of egg and dart form are absent. Part of the lower border on the front and the whole of the border at one end of the back are missing. At one end of the casket only the upper and a part of the lower borders survive; at the other end (Fig. D, PI. 12) there are two plaques set in rosette borders, though here too the border at the bottom has been lost. The rosette bands are all of the type characteristic of the caskets, but they are not as delicately carved as are those of the finest examples.

1. A. Goldschmidt and K. Weitzmann, Die Byzantinischen Elfenbeinskulpturen der X. bis XIII. Jahrhunderts, Berlin, 1931, Vol. I.

2. D. Talbot Rice, Masterpieces of Byzantine Art, Edinburgh, 1958, nos. 79 and 137. 
The plaques all bear warriors or similar figures, vigorously rendered, but somewhat roughly carved. The repertory is less varied than on many caskets of the same type illustrated by Goldschmidt and Weitzmann (Nos. 8 to 12), for there are no very clearly recognisable classical scenes, like the struggle of Hercules, no monsters, like the chimeras and winged gryphons so popular on many of the caskets, and no centaurs nor erotes. The figures, in fact, are mainly restricted to warriors in diverse poses.

Few exact parallels can be found; the nearest are some of the plaques of a casket in the Castello at Milan ( $G$ and W. no. 8), but even here there are none that are exactly the same, while the general theme of the iconography is distinct, for on the Milan casket many of the figures belong to the Joshua story, whereas on that at Edinburgh none of them do. Stylistically, however, the two caskets are closely related; they might well have been done in the same workshop, and are certainly of the same date. Goldschmidt and Weitzmann date the Milan casket to the tenth century; the eleventh would perhaps seem more likely, for the figures are very stylised; in the tenth one would have expected them to be rather freer.

The second casket (No. 1884: 44:10) is of the same shape as the first, but is rather smaller, being $27.5 \mathrm{~cm}$. long, $13.8 \mathrm{~cm}$. wide, and $10.7 \mathrm{~cm}$. high. On the lid is a long panel bearing nude maenads in very contorted poses (Fig. E, Pl. 13). The two to the right hold wreaths, the two to the left what appears to be Heracles' lyre. The plaque is bordered at the sides by rosette bands of the usual type, and there must have been similar rosette bands at the ends, but these have been lost. The margin, under which the lid slides, is decorated with a formal pattern, shaped like a repeated capital M ; it is perhaps a derivative of a stylised scroll. The sides are made up of similar long, narrow panels, bordered above, below and at the ends by rosette bands. On one side there are two lions at one end and a hare and two dogs amidst foliage at the other (Fig. F, Pl. 13); on the other side there is a gryphon at one end, which is chasing an animal which is presumably a horse amidst scroll work; at the opposite extremity are two smaller gryphons, confronted; a portion of the rosette border is missing behind the first gryphon (Fig. G, Pl. 14). At one end of the casket the ivory has all disappeared; at the other there is a small panel bearing a winged gryphon attacking a hare. At its sides and bottom this plaque is bordered by rosette bands; above is a narrower border composed of squares of four dots separated from one another by a sort of double dart pattern (Fig. H, Pl. 14). 
The rosettes of this casket are well carved and rather fresher than those on the first. The plaques, if their extreme degree of stylisation is allowed for, show work of high quality.

Goldschmidt and Weitzmann illustrate several caskets decorated in the same very distinctive style, though on none of them are all of the motifs we see on the Edinburgh example exactly paralleled. The most similar is a casket in the Museo Civico at Pesaro (G. and W., No. 63), where the same scene of maenads with Heracles' lyre and the struggle of a winged gryphon with another animal are depicted. The same fantastic animals appear again on a casket at Ravenna (G. and W. No. 60). Both these caskets are dated by Goldschmidt and Weitzmann to the twelfth century, and constitute, with others, a late sub-group of the class they call "Classicising". They compare the ornament to sculptures in stone above the entrance of the church of St Zeno at Verona (Abb. 21, p. 44), which they suggest must have been inspired by a Byzantine ivory.

The classical heritage of the scene on the top, with its nude figures, is clear, however distaat it may be, while the themes of the animal decoration follow on from those usual in mosaic floors of early Byzantine times, notably that of the Great Palace at Constantinople. But the carver of the ivory was obviously more at home when doing the elegant, scroll-like, animals at the sides than he was when doing the more naturalistic maenads on the top. He must, in fact, have worked in a school where a formal, decorative style was favoured, much in the way that it was interpreted by artists in the Celtic world. It therefore seems tempting to suggest that the caskets of this group might perhaps have been carved somewhere in northern Italy, where the same animal repertory was very popular in stone carving, rather than in Constantinople. But there remains the question of the rosettes, which are typically Constantinopolitan, and of high quality. Could strips of rosettes have been exported, ready carved? If so the caskets might have been put together in northern Italy, after the animal plaques had been carved specially for them.

D. TALBOT RICE 


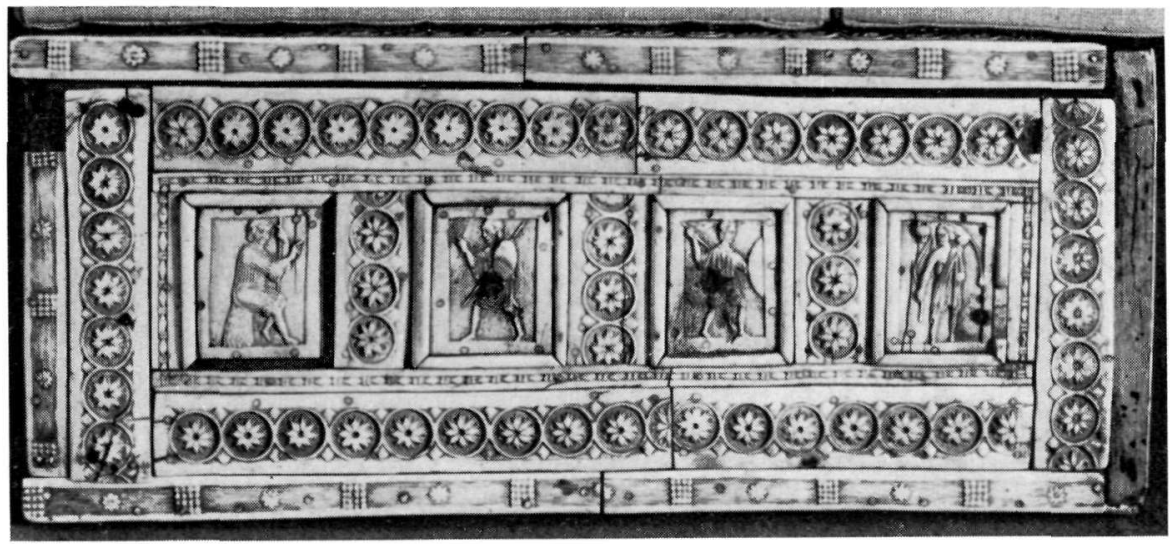

Fig. A.

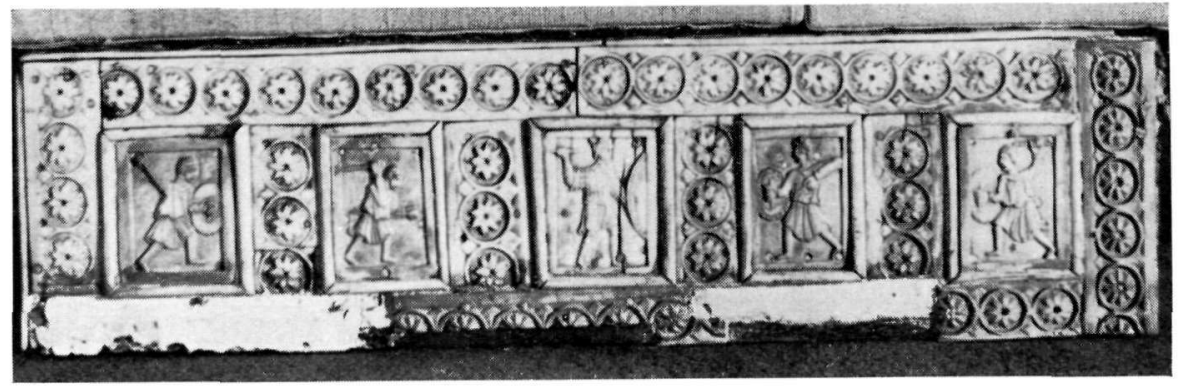

Fig. B.

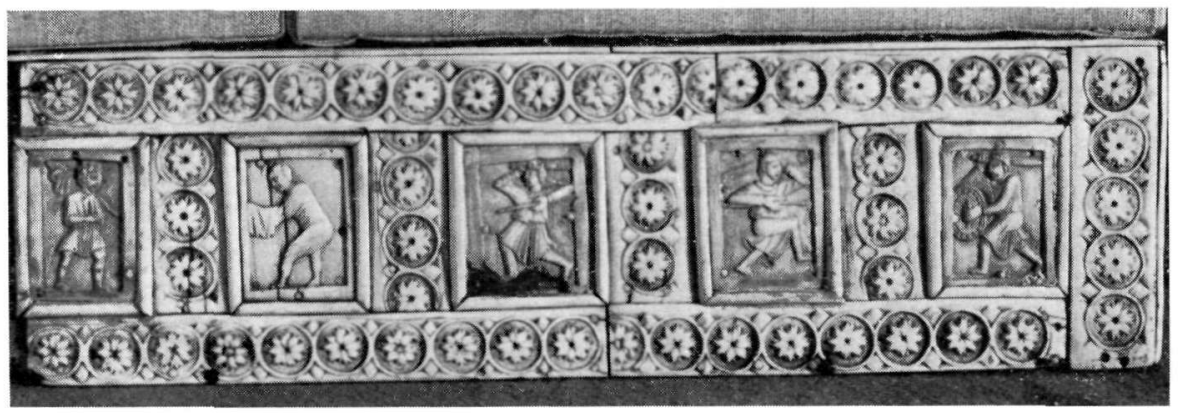

Fig. C. 


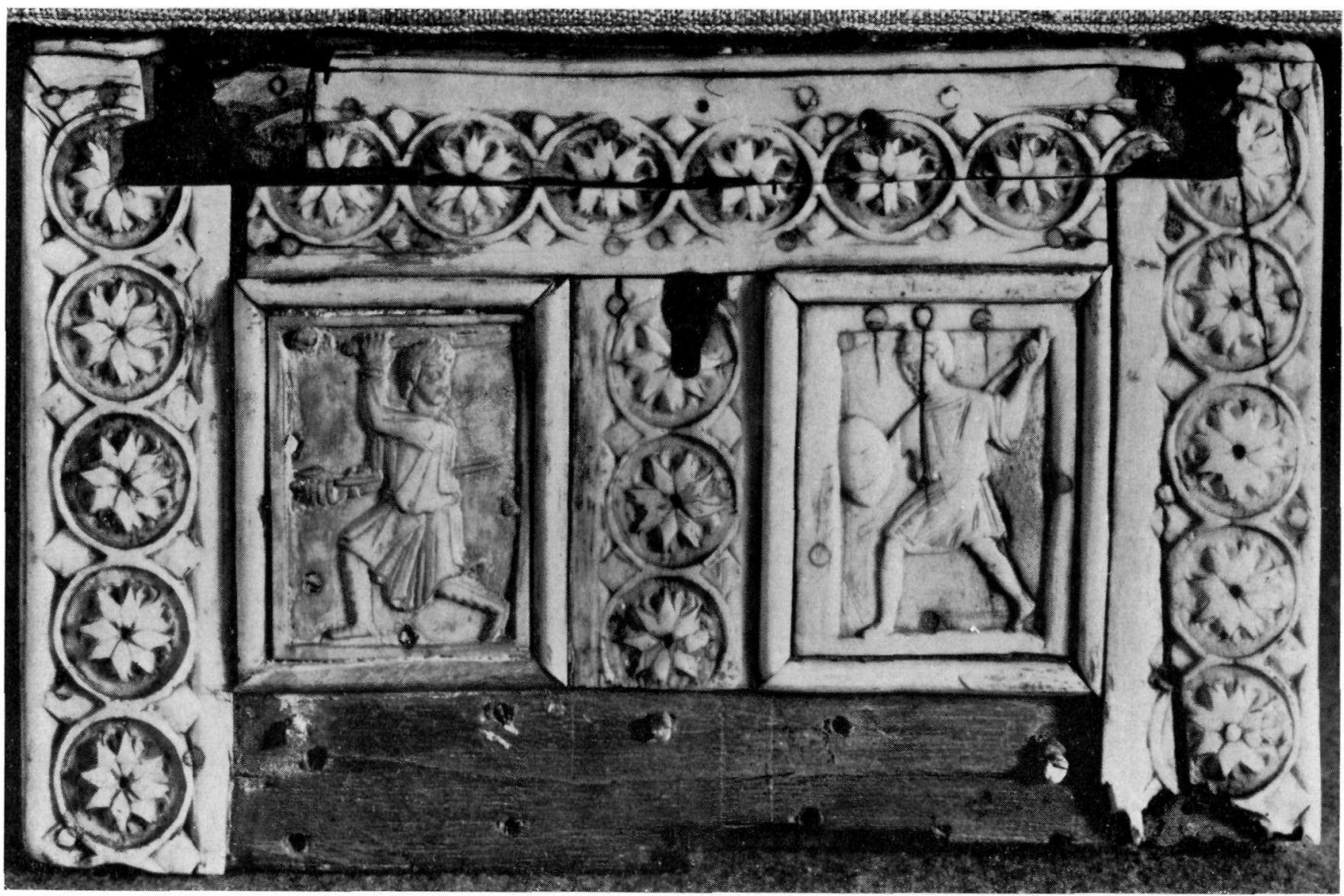

Fig, D. 


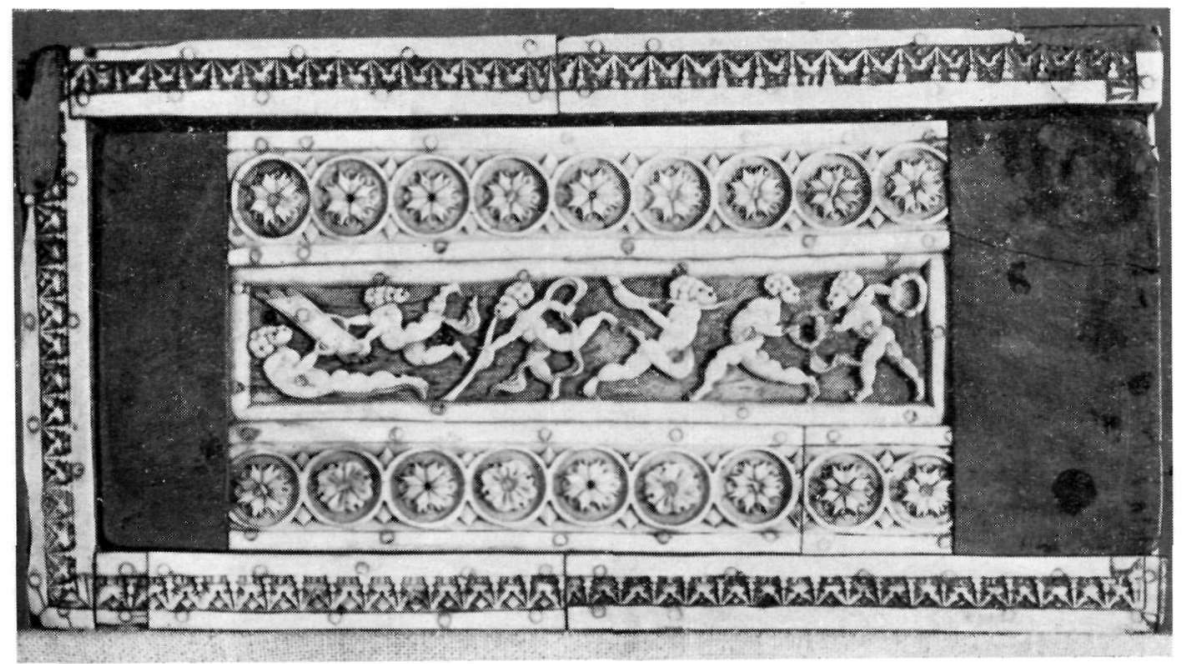

Fig. E.

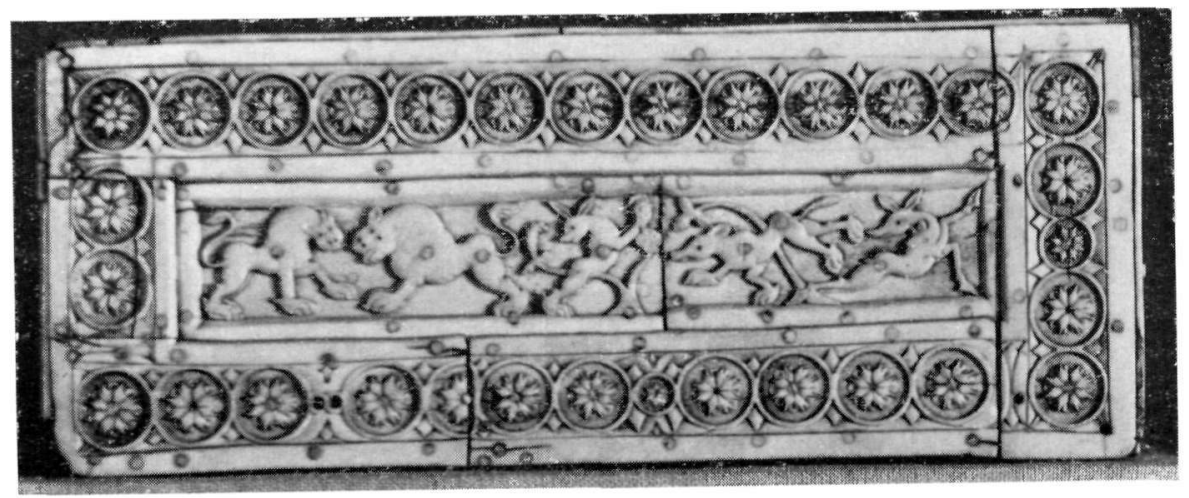

Fig. F. 


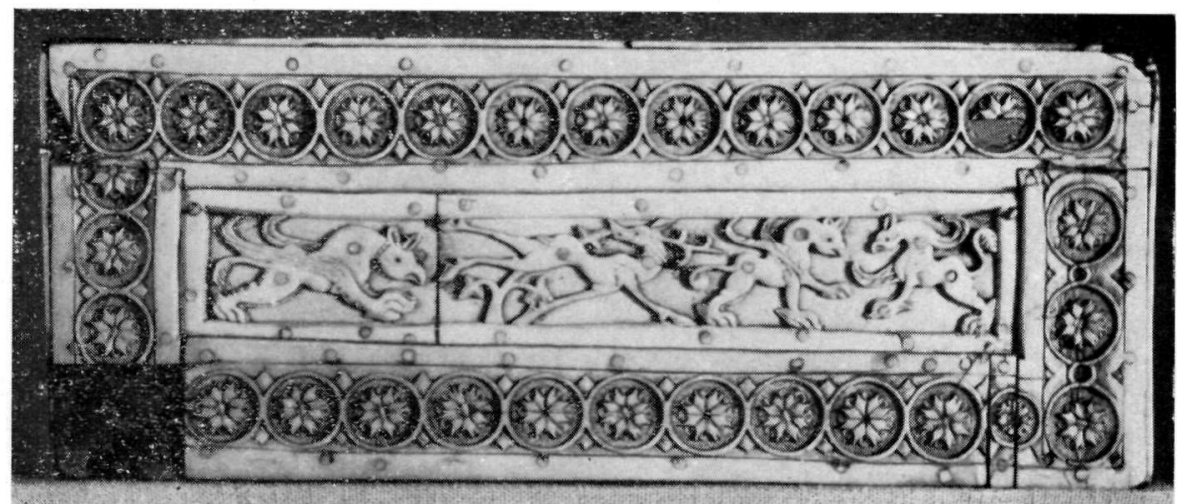

Eig. G.

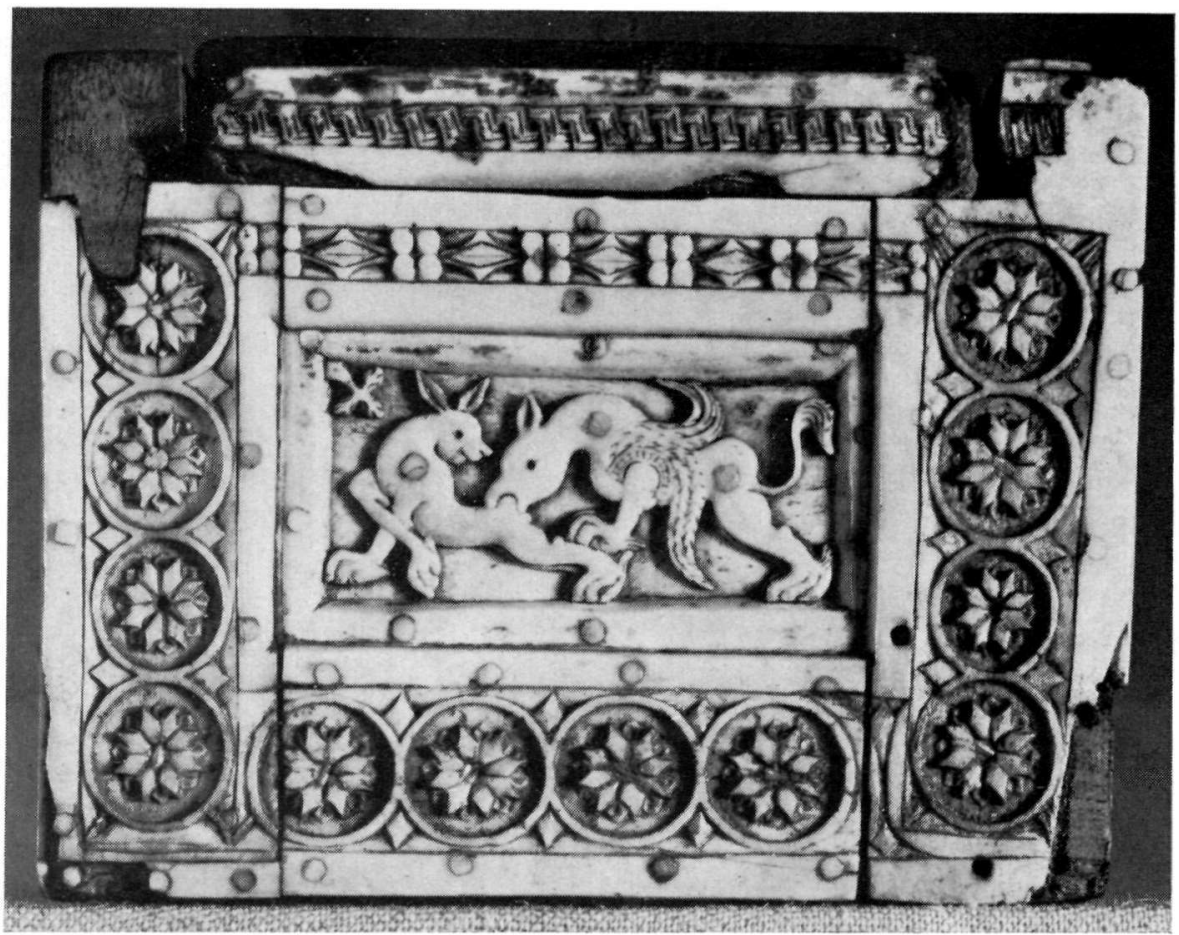

Fig. H. 